\title{
Intertidal invertebrate harvesting: a meta-analysis of impacts and recovery in an important waterbird prey resource
}

\author{
Leo. J. Clarke ${ }^{1, *}$, Kathryn M. Hughes ${ }^{2}$, Luciana S. Esteves ${ }^{1}$, Roger. J. H. Herbert ${ }^{1}$, \\ Richard A. Stillman ${ }^{1}$ \\ ${ }^{1}$ Department of Life and Environmental Sciences, Bournemouth University, Talbot Campus, Fern Barrow, Poole, Dorset, \\ BH12 5BB, UK \\ ${ }^{2}$ Natural Resources Wales, Maes y Ffynnon, Penrhosgarnedd, Bangor, Wales, UK, LL57 2DW
}

\begin{abstract}
Harvesting of marine invertebrates in intertidal areas often comes into conflict with conservation objectives for waterbird populations of the orders Anseriformes and Charadriiformes. We present a meta-analysis of the relationships between benthic invertebrate communities and various sources of intertidal harvesting disturbance to investigate impacts and recovery in bird prey resources. The effect size (Hedges' $d$ ) of harvesting on benthic species abundance, diversity and biomass was calculated for 38 studies in various locations globally, derived from 16 publications captured through a systematic review process that met the meta-analysis inclusion criteria. A negative response to harvesting disturbance was found for all taxa, including both target and non-target species, that represent important types of waterbird prey. Impacts appear most severe from hand-gathering, which significantly reduces the abundance of target polychaete species, a key prey group for many bird species. Across all gear types, non-target species demonstrate a larger reduction in abundance compared to target species. Recovery trends vary, with differences observed between taxonomic groups and gear/habitat combinations. Abundance of bivalve molluscs, a potentially highly profitable bird prey item, is suppressed for $>60 \mathrm{~d}$ by mechanical dredging in intertidal mud, while annelid and crustacean abundances demonstrate near recovery over the same period. Data suggest that recovery following harvesting in sandier habitats may in some cases take as long as or longer than in muddy sediments. We recommend management measures to minimise disturbance to benthic prey resources and support conservation objectives for waterbird populations to meet international legal requirements.
\end{abstract}

KEY WORDS: Fishing impacts · Intertidal $\cdot$ Invertebrates $\cdot$ Waterbirds $\cdot$ Prey abundance

\section{INTRODUCTION}

Commercial harvesting of marine invertebrates in soft sediment intertidal areas often comes into conflict with nature conservation interests, in particular the conservation of nationally and internationally important populations of waterbirds of the orders Anseriformes (ducks and geese, e.g. common shelduck Tadorna tadorna, common eider Somateria

\footnotetext{
${ }^{*}$ Corresponding author: lclarke@bournemouth.ac.uk
}

mollissima) and Charadriiformes (waders, e.g. common redshank Tringa totanus, Eurasian oystercatcher Haematopus ostralegus) (Camphuysen et al. 1996, 2002, Auster \& Langton 1999, Atkinson et al. 2003, Ens et al. 2004). Populations of these birds heavily rely on the invertebrate prey resources in these intertidal areas during the non-breeding season and may compete with fishermen for the same resource (Ens et al. 2004, Roberts \& Jones 2009).

() The authors 2017. Open Access under Creative Commons by Attribution Licence. Use, distribution and reproduction are unrestricted. Authors and original publication must be credited. 
Shorebirds and waterfowl rely on intertidal prey resources to maintain body condition over winter and to fuel annual migrations between wintering, staging and breeding grounds (Goss-Custard et al. 2004, dit Durell et al. 2006). Shortages in suitable intertidal invertebrate prey may create suboptimal feeding conditions, leading to reduced individual body condition and increased mortality in waterbirds when their energetic requirements cannot be met (dit Durell et al. 2006). Different bird species forage on prey of various taxonomic groups and size classes, determined by factors such as bill morphology, digestive capacity and risk of bill damage (Goss-Custard et al. 2006, Rutten et al. 2006). Some wader species are more generalist feeders, consuming prey of a variety of groups and size classes, while others are more specific in their feeding habits. The preferred prey and winter intertidal habitat of common European bird species are listed in Table S1 in the Supplement at www.int-res.com/articles/suppl/m584p229_ supp.pdf.

Intertidal harvesting may remove or damage nontarget species (Jennings \& Kaiser 1998, Kraan et al. 2007), decrease benthic productivity (Kaiser et al. 2002, Pranovi et al. 2004) and elicit physical changes to seabed characteristics with associated changes to benthic community composition (Dayton et al. 1995, Jennings \& Kaiser 1998, Kaiser et al. 2002). As a consequence, reductions in prey abundance, density, quality and size (Dayton et al. 1995, Collie et al. 2000, Kaiser et al. 2006) are widely reported, with welldocumented case studies of mass mortality in waterbird populations as a result of human harvesting activities (Ens et al. 2004, Goss-Custard et al. 2004, Atkinson et al. 2010). More gradual and sub-lethal changes in shorebird assemblages have also been reported at individual sites, with numbers of wormeating birds increasing following shellfish removal (van Roomen et al. 2005, Atkinson et al. 2010).

While ecosystem-based management (EBM) of fisheries is a well-accepted concept, it is more usually considered in the context of large-scale offshore fisheries (Pikitch et al. 2004, Möllmann et al. 2014). Intertidal fishing is widespread in global coastal environments, ranging from small-scale hand collection and bait digging to commercial exploitation through dredging and other mobile harvesting gear (Kaiser et al. 2001). Of an overall annual value of approximately US\$129 billion from global marine fisheries (FAO 2014), the value of the global baitworm industry alone has recently been calculated as almost £6 billion (US $\$ 7.9$ billion), with calls for management of these resources commensurate to other fisheries
(Watson et al. 2017). The ease of access to the resource in such fisheries requires careful management for sustainability. In addition to burrowing fauna, species of commercial importance in intertidal areas may include biogenic reef-building species such as oysters Crassostrea spp. (Beck et al. 2011, Scyphers et al. 2011) and mussels Mytilus spp. (Buschbaum et al. 2009) that collectively provide important ecosystem services, such as carbon sequestration (Tang et al. 2011), coastal protection (Scyphers et al. 2011), water quality regulation and nutrient cycling (Nelson et al. 2004, Newell 2004) and fish nursery grounds (Harding \& Mann 1999, Scyphers et al. 2011).

Many intertidal areas that support commercially important stocks of invertebrates are low energy environments with well-consolidated soft sediments. Benthic communities in these habitats may be vulnerable to physical disturbance from mobile fishing gear including sediment re-suspension (Dayton et al. 1995, Stokesbury et al. 2011) and smothering (McLachlan 1996, Norkko et al. 2002), and may experience much longer recovery times than more dynamic sediments and their associated fauna (Wynberg \& Branch 1994, Kaiser et al. 1998, Collie et al. 2000, Dernie et al. 2003). A previous meta-analysis focussed on all marine habitats (Kaiser et al. 2006) demonstrated that intertidal habitats are severely affected by fishing activities that remove key ecosystem engineers such as clams and shrimp (Beukema 1992, Pauly 1995, Handley et al. 2014), inducing regime shifts from larger, slow-growing species of low fecundity towards more opportunistic, fast-growing and smaller biota.

EBM seeks to manage human activities, while acknowledging the interactions between all components of an ecosystem, maintaining ecosystem function and the provision of services (Pikitch et al. 2004). To achieve an EBM approach to the management of intertidal ecosystems subjected to harvesting activities, it is therefore necessary to understand the consequences of harvesting on other components of the system. EBM has previously been implemented in this regard following collapses of Eurasian oystercatcher and common eider populations in the Dutch Wadden Sea (Camphuysen et al. 2002, Verhulst et al. 2004), and tools such as individual-based models can help predict population effects and inform management decisions (Atkinson et al. 2003, Stillman et al. 2003). The recent certification of the Ben Tre hand clam fishery in Vietnam by the Marine Stewardship Council demonstrates an example of sound EBM of an intertidal fishery (Marine Stewardship Council 2016). 
The objective of this study was to undertake a meta-analysis to quantify the effect of intertidal harvesting activities on benthic waterbird prey. Metaanalysis is becoming increasingly popular as a tool for ecologists (Koricheva et al. 2013) to answer questions at a broader scale than is possible in a single study (Collie et al. 2000), and to identify more generally applicable trends and relationships that might inform management decisions in a more statistically powerful way. This study therefore addresses the following research questions: (1) What is the immediate response of invertebrate prey to intertidal harvesting in the first $10 \mathrm{~d}$ following fishing? (2) How do the habitat and gear type used affect the magnitude of the response, and does this vary between taxa? (3) Does the response differ for target vs. non-target species of the fishery? (4) What are the recovery trends in intertidal communities following harvesting disturbance?

\section{METHODS}

\section{Data collection}

Data were extracted from publications that were identified by following a systematic review protocol (Hughes et al. 2014). A total of 16 publications, comprising 38 separate studies on intertidal harvesting disturbance, met the inclusion criteria of this metaanalysis (Table S2 in the Supplement). Inclusion criteria were: (1) the publication should be a study of the quantitative biological response in invertebrate communities to actual or simulated harvesting disturbance in intertidal habitats, along with information on control or pre-fishing conditions, (2) information on the gear type and habitat type in which the study took place must be included, and (3) the study should report a mean value of the relevant biological metric, a measure of the variance and the sample size. A further 18 studies were identified as relevant from the systematic review but excluded from data analysis because they did not meet the inclusion criteria (Table S3).

A 'study' was defined as an individual manipulation or observation of the response of benthic communities to intertidal fishing. Factors such as the harvesting gear type, scale and extent of the disturbance, habitat type, geographic region, the taxonomic level (e.g. phylum, species or community) of the reported outcomes or the sampling gear used are treated as predictor variables. When a publication reported results from, for example, experimental har- vesting in 2 different habitats, these 2 different habitat treatments were considered as 2 separate 'studies'. Habitats were differentiated according to the Folk sediment classification scheme (Folk 1954). This was done based on information provided in the publication on the relative proportion of different particle size categories.

\section{Response variables and effect size}

Studies reported a range of community metrics including species abundance, biomass, diversity indices, richness, evenness, primary productivity and the abundance of specific feeding traits (e.g. suspension feeders). However, these were often not relevant to the research questions and did not occur with sufficient replication among our population of studies. Thus for the purpose of this paper, we focus only on taxa abundance, biomass and diversity indices. Benthic invertebrate abundance and biomass are clearly key factors in determining prey availability and thus energetic intake rates in coastal waterbirds. Changes in diversity indices may indicate a shift in invertebrate community composition, with implications for waterbird assemblages that are often comprised of species that preferentially feed on different taxonomic groups. Furthermore, diversity provides an indication of the resilience of benthic ecosystems to environmental change (Folke et al. 2004). The response in the Shannon-Wiener index, Simpson's index and species richness were pooled for this analysis, given that the direction of the response to fishing will be consistent across all measures (i.e. a lower value of each measure indicates a reduction in diversity).

The size of the effect for each response was calculated as the standardised mean difference in fished conditions when compared to control conditions, or Hedges' $d$, using

$$
d=\frac{\left(X_{1}-X_{2}\right)}{V_{\text {within }}}
$$

where $X_{1}$ and $X_{2}$ are the sample means of the 2 groups (e.g. fished and unfished areas) and $V_{\text {within }}$ is a measure of the within-study variance:

$$
\sqrt{\frac{\left(n_{1}-1\right) S_{1}^{2}+\left(n_{2}-1\right) S_{2}^{2}}{n_{1}+n_{2}-2}}
$$

where $n_{1}$ and $n_{2}$ are the group sample sizes and $S_{1}$ and $S_{2}$ are the standard deviations of the 2 groups. All analyses were carried out within R Studio (Version 0.98.1062) and the R metafor package (Viechtbauer 2010). 


\section{Combining effects}

In most cases, a study reported the response of multiple species to fishing disturbance. In order to assess impacts upon the benthic community as a whole, a 'study-level' effect was calculated by combining the effect size (Hedges' $d$ ) for data from individual species reported within that study. The combined effect size for a study was calculated as the mean of the response across all species.

When calculating the variance of the study-level effect size, it must be considered that the responses of each species to fishing disturbance in the study may not be wholly independent of one another. The level of correlation between the outcomes must therefore be taken into account. The variance of the study-level effect size was calculated using

$$
\operatorname{Var}=\left(\frac{1}{m}\right)^{2}\left(\sum V_{i}+\sum\left(r_{i j} \sqrt{V_{i}} \sqrt{V_{j}}\right)\right)
$$

where $m$ is the number of outcomes reported within the study, $V_{i}$ is the variance of the $i^{\text {th }}$ outcome, and $r_{i j}$ is the correlation between the outcomes with variances of $V_{i}$ and $V_{j}$. Study-level variances may be calculated using $r=1$ (assuming complete correlation) or $r=0$ (assuming full independence). The former is likely to overestimate the variance and underestimate the precision, while the latter is likely to underestimate the variance and overestimate the precision (Sciberras et al. 2013). In order to avoid the consequences of working with these extreme assumptions, $r=0.5$ was used when combining effects.

An overall summary effect was then calculated as the mean effect size across all studies using a random-effects model, such that weight is assigned to each study as the inverse of its variance (i.e. 'study' is included as a random effect and more weight is assigned to studies with less variance) (Borenstein et al. 2009). When results of this model indicated significant heterogeneity between study-effect sizes, the effect of additional moderating variables added to the model (such as habitat, gear type, region etc.) was investigated.

\section{Initial impacts}

In order to investigate the initial impacts of intertidal fishing disturbance, we combined data across $0-10 \mathrm{~d}$ after fishing. While using this method may mask some of the short-term variation in the effect of fishing during the first few days after disturbance, it has the benefit of nullifying potential effects of scavengers on the measured responses and makes the dataset more balanced for analysis (Kaiser et al. 2006). Once Hedges' $d$ was calculated for all studies, a summary effect size at 0-10 d post-fishing was calculated using the methods described above. This summary effect size was first calculated as the mean across all taxa, before investigating the initial impacts on the main taxonomic groups in the data that represent key prey groups for coastal waterbirds in the intertidal. These included annelid worms, crustaceans and molluscs. Individual species effect sizes were also calculated for the common cockle (Cerastoderma edule, Cardiidae), Baltic tellin (Macoma balthica, Tellinidae), catworms (Nephtys spp., Nephtyidae), mudsnail (Hydrobia ulvae [now Peringia ulvae], Hydrobiidae) and spionid polychaetes Scoloplos spp. (Spionidae).

\section{Moderating variables}

Further analyses followed the methods used by Kaiser et al. (2006) in a global review of the impacts of bottom-fishing on benthic habitats to investigate in more detail the effect of other predictors on the effect size. This allowed for a more intuitive analysis of the dataset against the research questions, providing more relevant insights into the overall trends in intertidal harvesting impacts for environmental managers and policy-makers.

\section{Habitat, gear and target vs. non-target species}

In order to further investigate the response of effect modifiers (e.g. habitat, gear type, target vs. non-target species) a more simplistic ANOVA approach was used to test for differences in the magnitude of the initial effect (0-10 d post-disturbance) between groups. By calculating summary-effect sizes across studies as described above, such factors are lost from the analysis, and this ANOVA approach allows for a more workable and balanced dataset for testing further hypotheses.

\section{Gear and taxa interactions}

In order to generalise the sensitivity of different taxa to different gear types, fishing gears were grouped together and a classification tree was created through recursive partitioning. This was done to assess the immediate post-harvesting effect of different gear types on the abundance of different taxonomic groups. 


\section{Recovery trends}

An ANOVA approach was also used to investigate recovery patterns for each gear/habitat combination present in the data as it allowed for a comparison of the magnitude of the effect between time points since fishing. Only abundance data were available with sufficient replication for this analysis of recovery in gear/habitat combinations. We grouped data from 0-10 d post-fishing, 11-50 d, 51-500 d and >500 d. This approach of categorising data, while resulting in the 'loss of fine-scale variation in the response time to post-fishing' (Kaiser et al. 2006, p. 3), allows the differences in the response across these time periods to be identified more effectively. For this recovery analysis, we included data for all taxa present in each gear/habitat combination regardless of the direction of the initial response to harvesting, as to assess recovery only in those taxa that demonstrate a negative initial response would introduce selection bias and allow for artefactual evidence of recovery (Kaiser et al. 2006). For each gear/habitat combination that showed an effect of time, we then reanalysed the data using linear regression with log +1 transformed time since fishing in days as a continuous variable. Analysis of covariance (ANCOVA) was first carried out for these data, and where no difference in the slope of the response between taxonomic groups was identified, the data were pooled. Recovery may not always be linear, and in some cases a curvilinear relationship better fit the available data, in which case a generalised additive model (GAM) was used to represent the recovery trend. In this analysis, recovery was considered to occur at the point at which non-significance of the effect from control conditions is evident, equivalent to a $5 \%$ significance level test and rejecting the null hypothesis of no impact. Only a subset of the data reported changes in diversity and biomass, and this was therefore integrated across all habitats, gears and taxa present in the data and analysed using the ANOVA approach described above to investigate initial impacts and subsequent recovery.

\section{Analysis notes}

As Kaiser et al. (2006) discussed in great detail, from a purely statistical standpoint there are issues in the ANOVA analysis of our meta-database, not least a largely unbalanced dataset and non-independence of individual data points that are often derived from the same study. Strictly speaking, each study should contribute only a single data point to our analysis due to the inherent variation in habitats, gear types and geographic locations. However, to introduce 'study' as a random effect into our ANOVA analyses to recognise this variation at the study level, while also appropriately accounting for gear, habitat, time and individual taxa responses, would reduce the available degrees of freedom to a level at which no model could be constructed.

Although averaging the response across all taxa in our ANOVA introduces the problem of within-study correlations, it is preferred over reducing the data to a single response for each study. Consistent with Kaiser et al. (2006), a reduction in residual degrees of freedom to the magnitude of the number of studies would only occur if taxa were perfectly correlated, and in reality any within-study correlation will simply reduce the degrees of freedom of the F-statistics to some extent compared to those quoted here.

Given such challenges, rather than constructing an unworkable model, we have taken the somewhat optimistic approach of Kaiser et al. (2006), and we echo their caveats when interpreting our results and plots; although our methods may be viewed as statistically naïve, they allow for a more intuitive analysis for the reader and for policy-makers. Given these caveats, it is encouraged that emphasis should be placed on the higher-level trends and relative recovery patterns that this study identifies, which are unlikely to be affected by non-independence. With this in mind, the number of observations from which mean responses are derived is indicated in each of our plots for context to aid the reader in interpreting results.

\section{RESULTS}

\section{Studies}

The majority of studies that met the inclusion criteria were carried out in Northern Europe (Table 1), with most undertaken in the UK. Hand gathering comprised the majority (27 of 36 ) of the harvesting techniques investigated by the studies, with hand digging and hand raking the most commonly studied harvesting types (Table 1). This may be due to the fact that the use of hand gathering techniques, and therefore the ease of studying these techniques, is relatively low cost and requires few resources, in addition to the logistical ease of carrying out these studies. Most studies focussed on the use of fishing gears in sandy and muddy 
Table 1. Number of studies ( $\mathrm{n}=38$ from 16 publications) included in the analysis with regards to the region, gear type and habitat within each study. A complete list of the publications used in this analysis is provided in Table S2 in the Supplement at www.int-res.com/articles/suppl/m584p229_supp.pdf. Habitats — (g)mS: gravelly/muddy sand; M: mud; mS: muddy sand; msG: muddy/sandy gravel; S: sand; sM: sandy mud

\begin{tabular}{|lclccc|}
\hline Geographic region & $\begin{array}{c}\text { No. } \\
\text { studies }\end{array}$ & Harvesting technique & $\begin{array}{c}\text { No. } \\
\text { studies }\end{array}$ & Habitat & $\begin{array}{c}\text { No. } \\
\text { studies }\end{array}$ \\
\hline Australia & 1 & Hand digging & 11 & $(\mathrm{~g}) \mathrm{mS}$ & 1 \\
North America & 8 & Hand pump & 3 & $\mathrm{M}$ & 5 \\
Northern Europe & 22 & Hand raking & 13 & $\mathrm{mS}$ & 12 \\
South Africa & 4 & Hydraulic dredge & 5 & $\mathrm{msG}$ & 1 \\
Southern Europe & 3 & Mechanical dredge & 6 & $\mathrm{~S}$ & 12 \\
& & & & $\mathrm{sM}$ & 7 \\
\hline
\end{tabular}

habitats. The dominance of these habitats in the dataset likely represents their geographic extent and the association of the target species with a specific habitat.

\section{Initial impacts}

\section{Taxonomic response}

Fishing activity caused a significant reduction in the average abundance across all taxa (across all habitats and gears) in the first $10 \mathrm{~d}$ following disturbance, with a weighted mean Hedges' $d$ estimate of -0.55 (95\% CI: -1.06 to $-0.005, z=-2.15, p<0.05$ ). This indicates that abundance is on average $42 \%$ lower in harvested plots than in non-harvested plots across all studies (Table 2). All 3 of the main taxonomic groups for which data were available were reduced in abundance immediately (0-10 d) following fishing disturbance, although only annelids show a significant response (Table 2).

The results of the random-effects model on all abundance data suggest considerable heterogeneity between the study effect sizes (test of heterogeneity:

Table 2. Weighted mean summary effect sizes from randomeffects models for the main taxonomic groups at 0-10 d following fishing disturbance. On average, overall abundance across taxa was $42 \%$ lower in harvested plots than in non-harvested plots across all studies. Values in bold are significant $(p<0.05)$

\begin{tabular}{|lcccc}
$\begin{array}{l}\text { Taxonomic } \\
\text { group }\end{array}$ & Hedges' $d(95 \%$ CI $)$ & \% change & $z$ & $p$ \\
\hline Mean & $-0.55(-1.06$ to -0.05$)$ & -42.31 & -2.15 & $\mathbf{0 . 0 3 2}$ \\
Annelida & $-0.50(-0.82$ to -0.18$)$ & -39.17 & -3.05 & $\mathbf{0 . 0 0 2}$ \\
Crustacea & $-0.35(-0.94$ to 0.24$)$ & -29.61 & -1.17 & 0.243 \\
Mollusca & $-0.42(-0.96$ to 0.14$)$ & -33.76 & -1.47 & 0.143 \\
\hline
\end{tabular}

$\mathrm{p}<0.001)$. Including gear type, habitat, and the minimum extent of the fishing disturbance as moderating variables in a mixed-effects model accounts for only $9 \%$ of residual variation in the model, with further unexplained variance remaining between the study outcomes, possibly accounted for by other variables not considered within the model, or introduced through sampling error (test of heterogeneity: $\mathrm{p}<0.001$ ). The effects of these additional variables are explored in further analysis presented below.

\section{Species-level response}

Summary effect sizes for individual species are reported in Table 3. Only Scoloplos spp., the deepest burrowing of the fauna reported, show a significant reduction in abundance (Table 3), although all species other than Macoma balthica indicate a reduction in abundance following harvesting.

\section{Effects of gear type and habitat}

Initial impacts of each gear type and habitat were first investigated separately (Fig. 1). Results show significant differences in the magnitude of the effect at $0-10 \mathrm{~d}$ post-fishing between gear types $\left(F_{4,287}=\right.$ 2.93, p < 0.05), when hand digging and the use of a mechanical or hydraulic dredge significantly reduce abundance. A post-hoc Tukey test showed that the use of a hand pump most negatively affects initial post-fishing abundance, significantly more so than mechanical and hydraulic dredging and hand raking. However, there is considerable variability around the mean effect size for this gear type.

Harvesting in sand, gravelly and muddy sand, muddy sand and sandy mud habitats causes significant initial reductions in abundance. The magnitude of the reduction between habitats is significant $\left(F_{4,287}=5.36, \mathrm{p}<0.001\right.$; Fig. $\left.1 \mathrm{~b}\right)$, with a decreasing trend in the severity of impacts from sandy habitats to sandy mud. No significant impact is evident in muddy sands and gravel. 
Table 3. Weighted mean summary effect sizes from random-effects models for each of the 5 main species for the period 0-10 d post-fishing. All of these species are known prey of waders and other avian predators. Only Scoloplos spp. show a significant $(\mathrm{p}<0.05$, value in bold) reduction in abundance

\begin{tabular}{|lcccc|}
\hline Species & Hedges' $d(95 \%$ CI) & \% change & $z$ & $\mathrm{p}$ \\
\hline Cerastoderma edule & $-0.27(-0.56$ to 0.02$)$ & -23.58 & -1.80 & 0.071 \\
Macoma balthica & $0.13(-0.24$ to 0.50$)$ & +14.09 & 0.70 & 0.483 \\
Nephtys spp. & $-0.18(-0.56$ to 0.21$)$ & -16.18 & -0.90 & 0.370 \\
Hydrobia (Peringia) ulvae & $-0.64(-2.34$ to 1.06$)$ & -47.25 & -0.74 & 0.461 \\
Scoloplos spp. & $-0.67(-1.08$ to -0.26$)$ & -48.78 & -3.19 & $\mathbf{0 . 0 0 1}$ \\
\hline
\end{tabular}
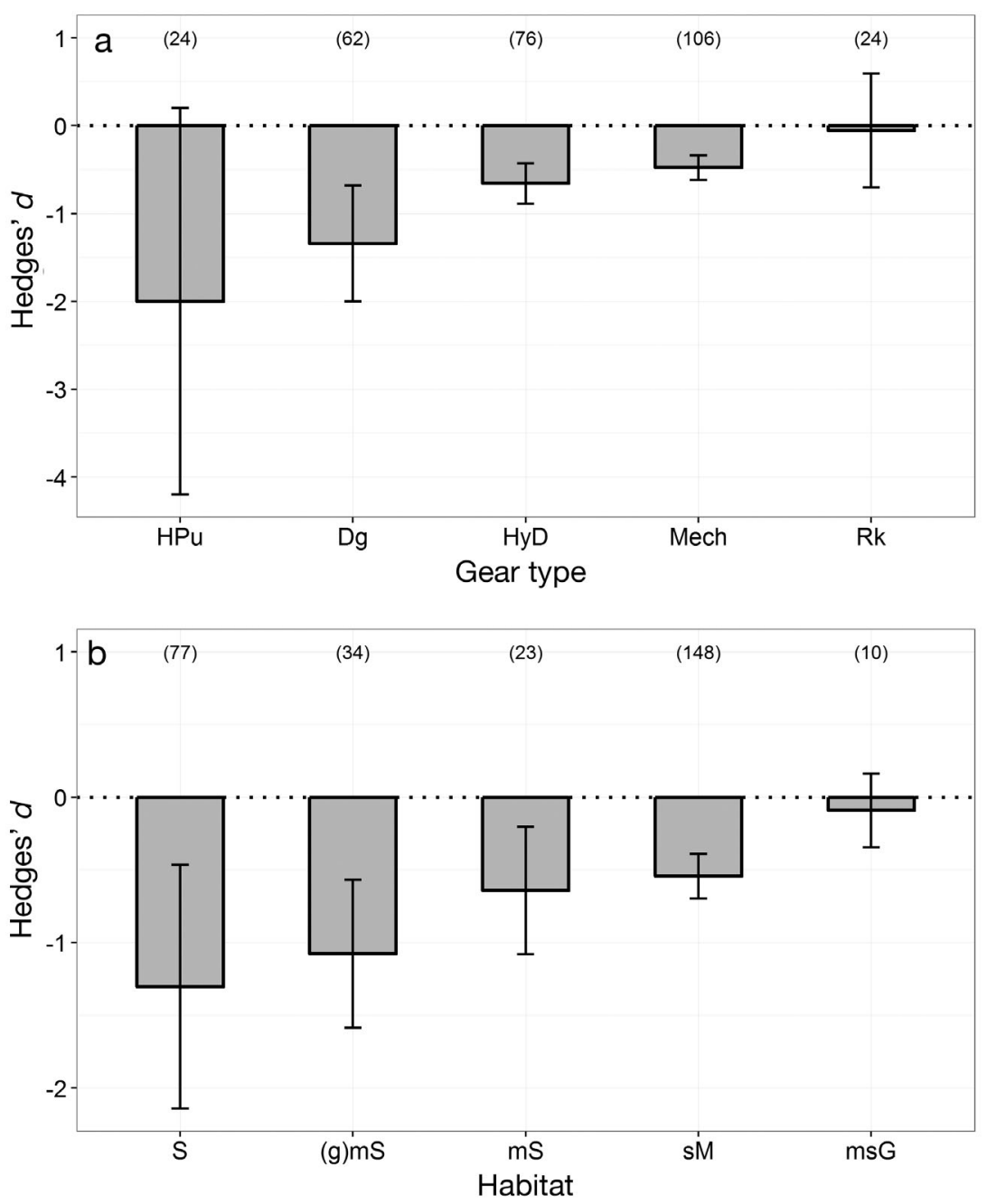

Fig. 1. Mean $( \pm 95 \% \mathrm{CI})$ effect of fishing disturbance on abundance of benthic taxa at 0-10 d post-fishing according to (a) fishing gear type and (b) Folk habitat group (Folk 1954). The horizontal dotted line represents no effect. Gear abbreviations - HPu: hand pump; Dg: hand digging; HyD: hydraulic dredge; Mech: mechanical dredge; Rk: hand raking. Habitat abbreviations - S: sand; (g)mS: gravelly/muddy sand; mS: muddy sand; sM: sandy mud; msG: muddy/sandy gravel. Adequate test for significant impact is whether the 95\% CI overlaps the horizontal zero effect line. Values in parentheses: number of observations

\section{Target vs. non-target species}

Given that no size data were reported in the meta-database, when the response of a target species was reported, we assumed that these were of harvestable size, where minimum landing sizes may apply. One study did differentiate between juvenile and adults of the target species, and data on juveniles was therefore omitted from this analysis. The abundance of target species might be expected to be most severely affected by fishing activities. However, there was no significant difference in the effect size on abundance of target or non-target species 0-10 d post-fishing. Initial impacts actually appear more severe for nontarget species than target species, with a mean Hedges' $d$ of -0.45 (95\% CI: -0.80 to -0.11 ) for target species and -0.82 (95\% CI: -1.09 to -0.56) for non-target species and a reduction of $37 \%$ compared to $56 \% \quad\left(F_{1,283}=2.86, \mathrm{p}=0.09\right.$; Fig. 2).

\section{Gear and taxa interactions}

Fig. 3 shows a classification tree of the size of the effect according to gear type on different phyla. For this analysis, hand raking, hand digging and hand pump were grouped into a single category ('hand gathering') to better generalise the sensitivities of different taxa to harvesting methods. Abundances of crustaceans appear more markedly reduced than other phyla (which are primarily annelids and molluscs) immediately after harvesting. However, the magnitude of the reduction in these taxa depends on the harvesting method. Hand gathering results in a more severe reduction in abundance (mean reduction of $93 \%$ ). For other phyla, there is no 


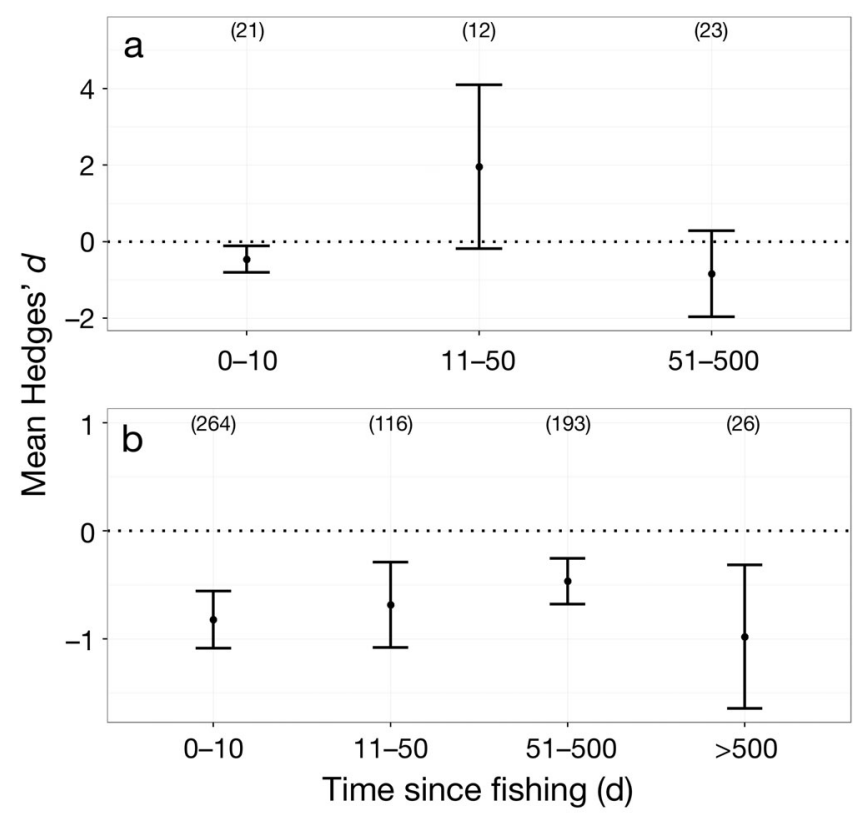

Fig. 2. Mean effect of fishing disturbance on the abundance of (a) target and (b) non-target species across time categories (no. of d) since fishing. The dotted horizontal line represents no effect. Adequate test for significant impact is whether the $95 \%$ confidence interval overlaps the horizontal zero effect line. Values in parentheses: number of observations

significant effect of gear type on the magnitude of the change in abundance (mean reduction of $48 \%$ across all gear types).

\section{Recovery patterns}

Target vs. non-target species

No significant effect of time is evident on the magnitude of the effect size for either target $\left(F_{2,53}=\right.$ $3.05, \mathrm{p}=0.06)$ or non-target $\left(F_{3,595}=1.83, \mathrm{p}=0.14\right)$ species. For non-target species, recovery (i.e. nonsignificance of the effect) does not appear $>500 \mathrm{~d}$ post-fishing; in fact, a further reduction in abundance occurs at this time, potentially suggesting delayed impacts. However, this analysis is integrated across all habitats, and some habitats may demonstrate a trend towards recovery at 51-500 d (Fig. 2). The effect on target species is somewhat idiosyncratic, likely due to the low power for this group (Fig. 2a); the majority of the data report the response in non-target species abundance, resulting in fewer degrees of freedom in the analysis of target species.

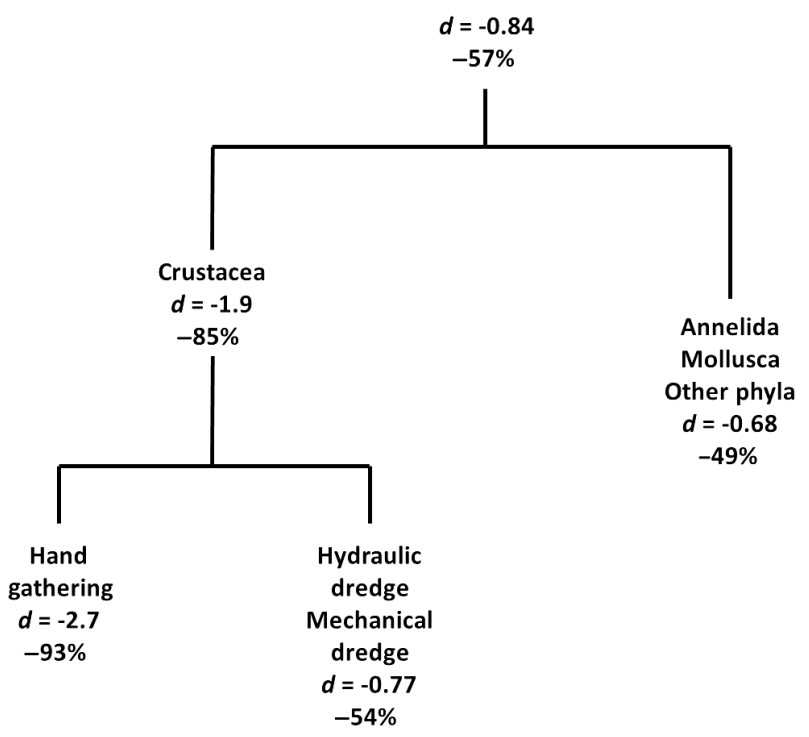

Fig. 3. Classification tree representing the interaction between fishing gear and taxonomic group with regards to changes in abundance 0-10 d post-fishing. Each node presents a partition in the data. For the data at each branch of the tree, the mean effect (Hedges' $d$ ) is given, along with the mean percentage change in abundance. Other phyla: Echinodermata, Phoronida, Nemertea

\section{Gear/habitat combinations}

Due to a paucity of data for gear types used in each habitat, the Folk habitat classifications used in previous analyses were grouped together into broad 'mud' and 'sand' categories. Fig. 4 presents the trends over time for the response in benthic abundance for each gear/habitat combination present in the data. The data indicate that all fishing gears cause a reduction in abundance in each habitat during the first period following fishing, with the exception of hand digging in mud and hand raking in sand, which cause a slight increase in abundance. Recovery trends for most gear and habitat combination appear unstable and highly variable.

Results indicate significant changes in the magnitude of the effect across time points for hand raking and mechanical dredging in sand and for hydraulic and mechanical dredging in mud (Table 4). Figs. 5 $\& 6$ indicate the recovery trends of those gear/habitat combinations that showed an effect of time on taxa abundance. A significant difference from control conditions is taken as when the model confidence intervals do not overlap with zero, and recovery as indicated by the model is taken as the point at which the confidence interval overlaps the horizontal line of no effect. A difference between phyla in the recovery slope from mechanical dredging in 


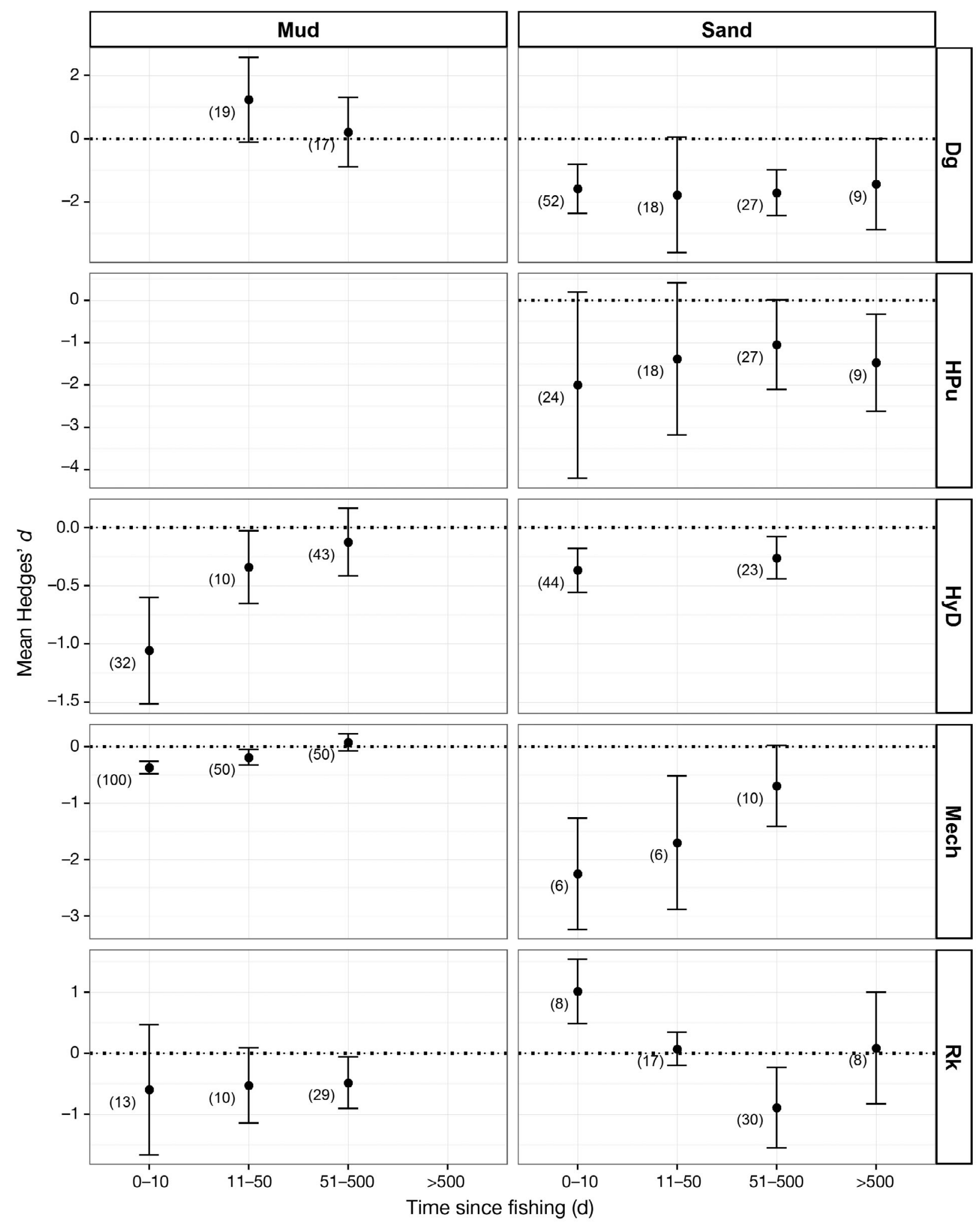

Fig. 4. Response in taxa abundance to fishing disturbance across 4 time categories following fishing. Data are mean response $\pm 95 \%$ CI. Significant deviation from zero effect (i.e. no response) is considered to occur if the error bars do not overlap with the dotted horizontal line. Gaps in the data are present for some gear/habitat combinations. Gear abbreviations - Dg: hand digging; HPu: hand pump; HyD: hydraulic dredge; Mech: mechanical dredge; Rk: hand raking. Values in parentheses: number of observations 
Table 4. One-way ANOVA of abundance of pooled taxa between grouped time categories for each gear/habitat combination for which sufficient data were available to undertake the analysis. Data for other gears and habitats were too scarce for this analysis; nd: no data available for that gear/habitat combination. Bold: significant $(p<0.05)$

change in the magnitude of the effect across grouped time periods

\begin{tabular}{|c|c|c|c|c|c|c|}
\hline \multirow{2}{*}{ Gear type } & \multirow[b]{2}{*}{$F$} & \multicolumn{2}{|c|}{- Sand $-H$} & \multirow[b]{2}{*}{$F$} & \multirow[b]{2}{*}{$\begin{array}{c}- \text { Mud } \\
\text { df }\end{array}$} & \multirow[b]{2}{*}{$\mathrm{p}$} \\
\hline & & $\begin{array}{c}\text { - Sand } \\
\text { df }\end{array}$ & $\bar{p}$ & & & \\
\hline Hand pump & 0.25 & 3,74 & 0.863 & nd & nd & nd \\
\hline Digging & 0.06 & 3,102 & 0.981 & 1.52 & 1,34 & 0.226 \\
\hline Raking & 7.90 & 3,59 & 0.000 & 0.03 & 2,49 & 0.975 \\
\hline Hydraulic dredge & 0.67 & 1,65 & 0.414 & 5.98 & 2,82 & 0.004 \\
\hline Mechanical dredge & 4.70 & 2,19 & 0.022 & 11.86 & 2,197 & 0.000 \\
\hline
\end{tabular}

Diversity and biomass

Diversity data (pooled species richness, Shannon-Wiener index and Simpson's index) indicate a mean Hedges' $d$ of 0.33 (95\% CI: -2.58 to 3.24 ) in the first $10 \mathrm{~d}$ following disturbance, representing a mean increase in diversity indices of $39 \%$ (Fig. 7a), although this is non-significant. The increase in diversity following fishing appears to subsequently decrease, with a significant reduction in diversity occurring 51-500 d post-fishing. By $>500 \mathrm{~d}$, the effect is non-significant, and no effect of time is observed on the magnitude of the response. The available biomass data indicate a significant reduction in benthic

mud is evident, with a decline in mollusc abundance compared to a positive trend (suggesting recovery) in other phyla $\left(F_{1,194}=26.50, \mathrm{p}<0.001\right.$; Fig. 5). While initial impacts may not be dramatic (and in fact data indicate no immediate decline), molluscs demonstrate no trend of recovery $60 \mathrm{~d}$ post-fishing; rather, they show a decline in abundance over this period.

For other gear/habitat combinations, ANCOVA of response data indicates no difference between the recovery slopes of different taxa, so data were pooled. The recovery trend for hydraulic dredging in mud indicates relatively short-term impacts on abundance, with a reduction in the effect size within $10 \mathrm{~d}$ post-fishing, and the model remaining close to no effect from around $10 \mathrm{~d}$ post-fishing for the remainder of the time period covered by the data (Fig. 6a), although there is some variability. The recovery trend for hand raking in sand appears more unstable, indicated by the low R-squared value and relatively poor fit of the GAM. It appears, however, that following a small initial increase in abundance, there is a further decline, with a small shift towards control or pre-harvesting conditions only after $400 \mathrm{~d}$ (Fig. 6b). Despite relatively few data points, recovery following mechanical dredging in sand (Fig. 6c) indicates a positive trend, with the model confidence intervals suggesting at least partial recovery after $400 \mathrm{~d}$. biomass compared to control or pre-fishing conditions, and this remains across all time periods present in the data and $>500 \mathrm{~d}$ post-fishing (although based on only 4 data points; Fig. $7 \mathrm{~b}$ ). ANOVA of the response over time periods shows a change in the magnitude of the response $\left(F_{2,21}=7.80, \mathrm{p}<0.01\right)$, with a trend towards recovery by $>500 \mathrm{~d}$.

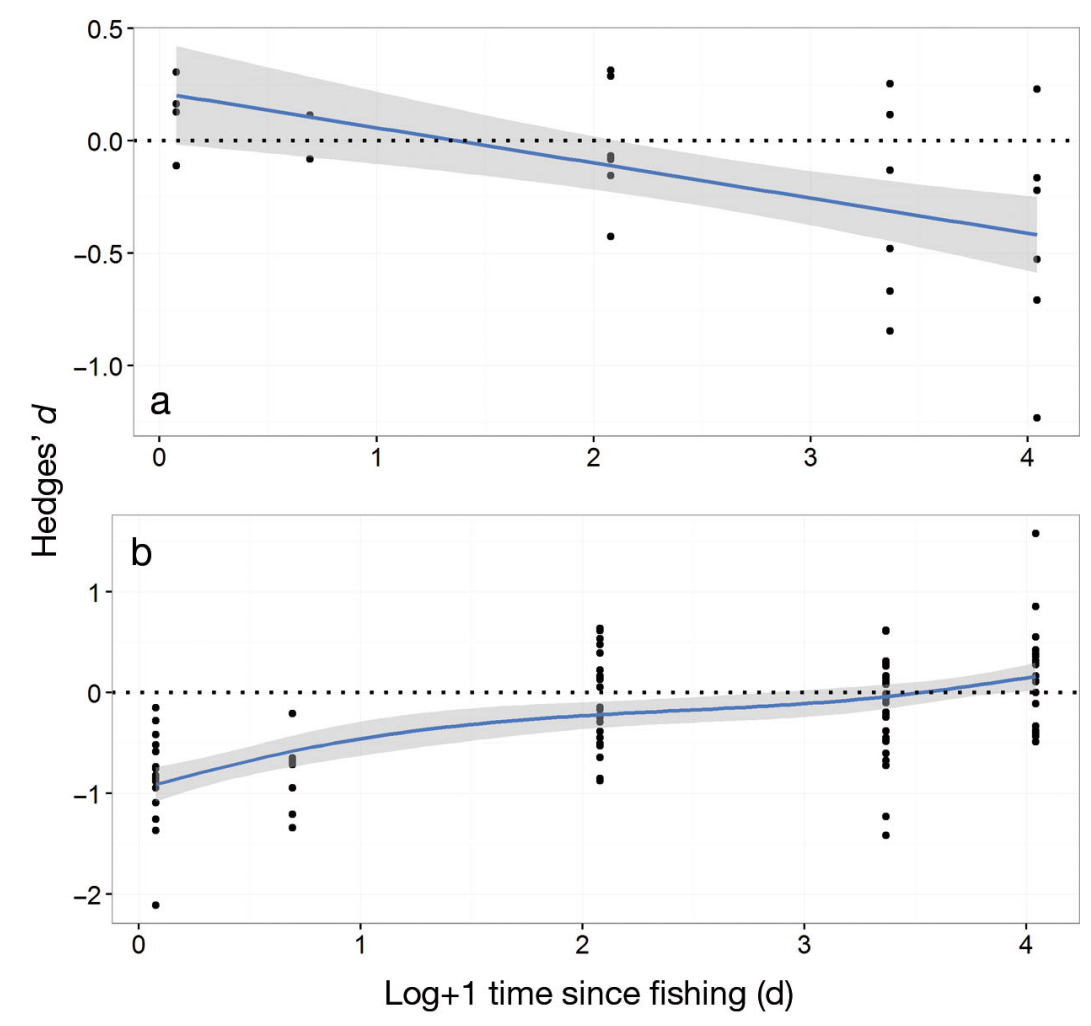

Fig. 5. Response (Hedges' $d$ : black circles) of (a) molluscs $\left(F=16.08, \mathrm{R}^{2}=\right.$ $0.28, \mathrm{p}<0.001)$ and (b) pooled taxa (annelids, crustaceans) $\left(F=32.86, \mathrm{R}^{2}=\right.$ $0.37, \mathrm{p}<0.001$ ) abundance to mechanical dredging in intertidal mud. Horizontal dotted line represents no effect. Blue line and grey shading: fitted model and $95 \% \mathrm{CI}$, respectively 

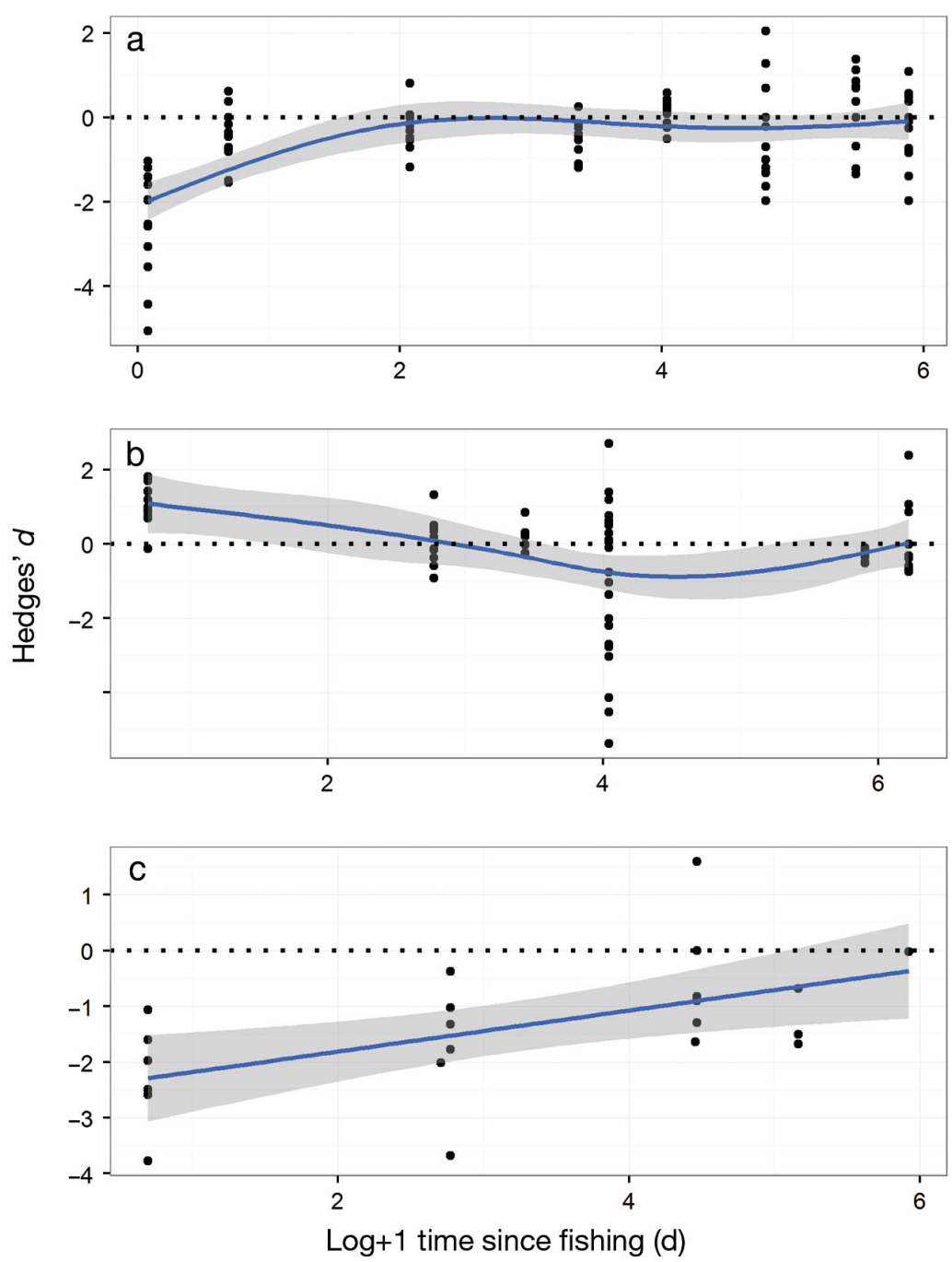

Fig. 6. Response (Hedges' $d$ : black circles) of benthic taxa to (a) hydraulic dredging in mud $\left(F=12.51, \mathrm{R}^{2}=0.31, \mathrm{p}<0.001\right)$, (b) hand raking in sand ( $\left.F \quad 4.20, \mathrm{R}^{2}=0.18, \mathrm{p}<0.01\right)$ and (c) mechanical dredging in sand $(F=8.83$, $\left.\mathrm{R}^{2}=0.27, \mathrm{p}<0.01\right)$. Horizontal dotted line represents no effect. Blue line and grey shading: fitted model and $95 \% \mathrm{CI}$, respectively.

\section{DISCUSSION}

Unlike bottom trawling in subtidal habitats, intertidal harvesting is often carried out more systematically given the direct access to the resource at low water. Furthermore, the depth to which intertidal fishing activities penetrate the habitat means that in many cases depletion of the biota is more extreme than for bottom-trawling (Kaiser et al. 2006). As it is possible to place sampling devices more precisely in an intertidal environment, sampling error in experimental studies is likely to be lower than for subtidal studies in which error is introduced due to vessel positioning issues. As a result, the data from inter- tidal studies should provide strong signals of fishing impacts when they occur.

Data from the first $10 \mathrm{~d}$ following fishing disturbance show overall significant reductions in the abundance of annelids, one of the main bird prey groups, and a significant reduction in the average abundance across all taxa. Annelid worms are often targeted with high accuracy through bait harvesting (Blake 1979, Watson et al. 2007), with harvesting efficiency of up to $70 \%$ reported in a study of digging for lugworm (Blake 1979). This higher efficiency is reflected in the larger initial reductions following the use of hand-held gears shown in Fig. 1. Furthermore, annelid worms may be sensitive to damage through non-target interactions with harvesting gear (Skilleter et al. 2005, Griffiths et al. 2006, Watson et al. 2007). Baitworm harvesting targets the larger species such as the king ragworm Alitta virens and lugworms Arenicola spp.; these represent key prey resources for worm-eating bird species such as common redshank Tringa totanus, black-tailed godwit Limosa limosa and Eurasian curlew Numenius arquata. In many places, hand techniques can be highly localised and small in scale, although in some areas the footprint of such practices combined may be thousands of square metres, as is the case in Poole Harbour in the UK (H. Fearnley, K. Cruickshanks, S. Lake, D. Liley unpubl.). However, this impact is still likely to be relatively limited compared to wide-scale commercial harvesting efforts that may cover hundreds of square kilometres (Piersma et al. 2001).

Annelid worms, along with crustaceans, another important prey group, appear to recover more quickly compared to other phyla, particularly molluscs. Molluscs are a key prey group for species such as Eurasian oystercatcher, common eider and red knot Calidris canutus, and data indicate that abundance can remain suppressed for $>60 \mathrm{~d}$ following dredging in muddy sediments (Fig. 5a). While molluscs are relatively sedentary, annelids and crustaceans are more motile, with potential for 


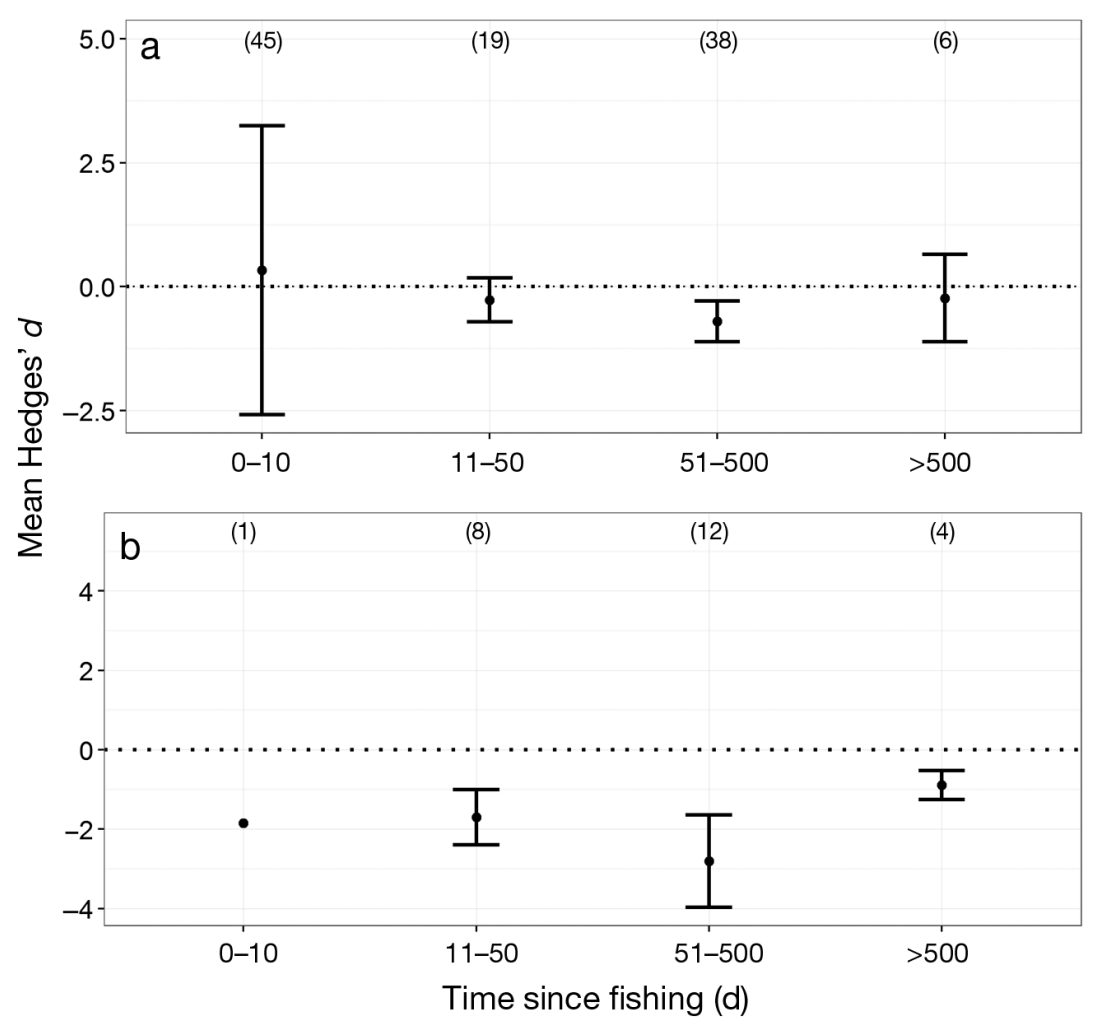

Fig. 7. Mean effect of fishing on (a) benthic diversity and (b) biomass across 4 time categories following fishing. Data are mean response $\pm 95 \%$ CI. Significant deviation from zero effect (i.e. no response) is considered to occur if the error bars do not overlap with the dotted horizontal line. Values in parentheses: number of observations

recolonization of an area through adult migration as well as larval dispersal (Pearson \& Rosenberg 1978, Levin 1984). Bivalve colonization relies on pelagic larval settlement, which is largely influenced by hydrographic conditions, or the subsequent migration of juveniles (Armonies \& Hellwig-Armonies 1992). Low spatfall levels that inhibit recovery coincide with periods of intensive fishing (Beukema 1992, Smit et al. 1998). Furthermore, the dominance of coarser sediments through the regular resuspension and loss of finer grain sizes, known as 'winnowing' (Martín et al. 2014), can result in poor feeding conditions for deposit-feeding bivalves (Taghon 1982, Kang et al. 1999), resulting in lower prey quality for molluscivorous birds. Recolonization of an area following mechanical shellfishing will generally require migration or settlement to occur over a much larger area than for recovery from more localised hand techniques, and long-term suppression of bivalve prey abundance and subsequent settlement may result (Ens et al. 2004). Such shifts to communities dominated by fast-growing worm species can subsequently lead to declines in populations of molluscivorous shorebird species and a shift towards more worm-eating waders (Atkinson et al. 2010).

Results show persistence of impacts in sandy habitats for longer than in muddy habitats, which is contrary to a prevailing view that physical recovery occurs relatively rapidly in sandier substrates and allows for earlier recolonization (Hall 1994, Jennings \& Kaiser 1998). Similar inconsistencies were identified in a previous, wider meta-analysis on general fishing impacts that found relatively low impacts of harvesting in mud and no obvious ranking of impacts across habitats (Collie et al. 2000). Fig. 1 indicates that harvesting in sand (all gears pooled) causes the largest initial reduction in abundance across all taxa, with less dramatic initial impacts in muddier habitats. At low tide, intertidal sand is much more safely accessible on foot than softer muddy habitats that remain unreachable, and hand harvesting at low water in sandy habitats may therefore be more intense and widespread. The temporal trends indicated in Figs. 4 \& 6 suggest that recovery in sand may be variable, with clear trends towards recovery only evident for hydraulic and mechanical dredging in sandy habitats. Conversely, recovery following the use of hand harvesting techniques (digging, hand pumping and raking) show less evidence of recovery and potentially delayed impacts. Again, hand harvesting is often very precise and disturbs sediment to a deeper depth than dredges that may only penetrate the sediment to a few centimetres. Furthermore, densities of species in muddy habitats are generally higher than in sandier habitats (Heck et al. 1995, Van Hoey et al. 2004), perhaps providing more potential for recolonization from neighbouring areas.

Hydrodynamic conditions overlying the affected habitat exert a large influence on biological recovery through the mediation of infilling rates of disturbed patches, causing considerable variation in recovery rates in different mud habitats (Dernie et al. 2003). This is an important consideration locally when predicting medium and long-term impacts following cessation of harvesting, particularly in intertidal areas of low energy where the substrate may be dominated by well consolidated finer sediments. 
While most intertidal harvesting causes a reduction in invertebrate abundance, hand digging in mud and raking in sand appear to cause an initial increase in all taxa pooled. Such techniques may allow for increased movement of scavengers or opportunistic invertebrate species into the area (Cesar \& Frid 2009) or bring deeper burrowing or infaunal species to the surface, temporarily increasing abundance and species diversity within the raked area. These techniques do not generally remove the sediment; rather it is left in situ, and bird predators are often observed to exploit these disturbed sites immediately after harvesting, before vacating the area, presumably after prey has been depleted (Ferns et al. 2000). Recovery trends of each of the gear/habitat combinations clearly differ (Fig. 4), and a more comprehensive multivariate analysis of the benthic assemblage may allow further insight into this trend, and identify such shifts in community composition (Sousa Leitão \& Baptista Gaspar 2007). Given that studies are undertaken across numerous locations and geographic regions, and therefore report the response in often vastly different sets of species from which a robust dataset for multivariate analysis could not be created, this type of analysis was not possible. Changes in diversity indices may provide some indication of changing dominance patterns in faunal communities (Fig. 7).

Non-target species may be significantly more affected than target species by intertidal fishing activities, with recovery patterns indicating prolonged effects. This is consistent with previous studies that have shown significant reductions of nontarget species up to $1 \mathrm{yr}$ after intertidal dredging (Kraan et al. 2007).

The changes to Dutch fisheries policy in the 1990s (Smit et al. 1998) demonstrate the need for adaptive management in intertidal fisheries, with consideration of more mechanised harvesting of species that have limited potential for recovery. The declines in the Wadden Sea Eurasian oystercatcher and common eider populations, and Eurasian oystercatchers in The Wash, UK (Atkinson et al. 2003, 2010), serve as reminders of the wider ecological implications of fishery mismanagement (Camphuysen et al. 1996, Smit et al. 1998). An important consideration in management of intertidal invertebrate resources is the size of prey which, while not reported in many studies, is an important factor in determining the available food for shorebird populations (Bowgen et al. 2015). Prey size can be an indicator of prey quality (in addition to abundance data alone), and is a strong determinant of an individual's energy intake and fitness (Bowgen et al. 2015).

Management measures to regulate the harvesting of intertidal organisms are already in place in many locations, largely through spatial and temporal restrictions on harvesting activity (Halpern \& Warner 2002, Halpern 2003), rather than limits on effort and allowable catch or harvests. Extensive research has demonstrated the effectiveness of marine reserves or no-take areas in subtidal ecosystems in conserving ecosystem function and productivity (Sciberras et al. 2013); the limited work carried out in intertidal habitats suggests the benefits may be comparable (Byers 2005, Griffiths et al. 2006).

Our results can contribute to ecosystem-based management and the achievement of sustainable fishing, while achieving conservation objectives of international requirements under the European Union Birds Directive (Directive 2009/147/EC) and similar national legislation. The evidence suggesting long-term detriment to waterbird prey from intertidal harvesting may have significant management implications. For policy-makers and environmental managers, the ranking of impacts in Fig. 1 and recovery trends shown in Figs. 4-6 are likely of most interest. Given the long-term impacts of dredging on mollusc abundance, we urge managers to ensure that shellfish harvesting is limited in order to secure sufficient adult stock, both as prey for waterbird populations and as a source of larval supply and for future population viability. In fact, much work has been done on the subject of calculating the amount of bivalve prey required to support waterbird populations over winter (Goss-Custard et al. 2004, Stillman et al. 2010, 2016, Stillman \& Wood 2013). Whether this is achieved through spatial and temporal restrictions, by assigning allowable catches or through effort limitations would likely be driven by local circumstance. Hand fisheries are often difficult to regulate due to the ease of access, although due to the evidence of prolonged impacts in hand fisheries presented here, along with their significant global value, we agree with Watson et al. (2017) that their management should be brought in line with other fisheries to ensure sustainability. The clear trends in recovery in annelids and crustaceans, common taxa targeted by hand, suggest that sustainability of such fisheries is certainly achievable with sufficient closures to allow adequate larval settlement or recolonization.

Acknowledgements. We thank Professor Michel Kaiser for his assistance in data collection and comments on draft versions of this manuscript. 


\section{LITERATURE CITED}

Armonies W, Hellwig-Armonies M (1992) Passive settlement of Macoma balthica spat on tidal flats of the Wadden Sea and subsequent migration of juveniles. Neth J Sea Res 29:371-378

*Atkinson PW, Clark NA, Bell MC, Dare PJ, Clark JA, Ireland PL (2003) Changes in commercially fished shellfish stocks and shorebird populations in the Wash, England. Biol Conserv 114:127-141

Atkinson PW, Maclean IM, Clark NA (2010) Impacts of shellfisheries and nutrient inputs on waterbird communities in the Wash, England. J Appl Ecol 47:191-199

Auster PJ, Langton RW (1999) The effects of fishing on fish habitat. In: Benaka L (ed) Fish habitat: essential fish habitat and restoration. Symposium 22. American Fisheries Society, Bethesda, MD, p 150-187

Beck MW, Brumbaugh RD, Airoldi L, Carranza A and others (2011) Oyster reefs at risk and recommendations for conservation, restoration, and management. Bioscience 61: 107-116

Beukema JJ (1992) Expected changes in the Wadden sea benthos in a warmer world: lessons from periods with mild winters. Neth J Sea Res 30:73-79

Blake RW (1979) Exploitation of a natural population of Arenicola marina (L.) from the north-east coast of England. J Appl Ecol 16:663-670

Borenstein M, Hedges LV, Higgins JPT, Rothstein HR (2009) Introduction to meta-analysis. John Wiley and Sons, Hoboken, NJ

Bowgen KM, Stillman RA, Herbert RJ (2015) Predicting the effect of invertebrate regime shifts on wading birds: insights from Poole Harbour, UK. Biol Conserv 186: 60-68

Buschbaum C, Dittmann S, Hong JS, Hwang IS and others (2009) Mytilid mussels: global habitat engineers in coastal sediments. Helgol Mar Res 63:47-58

Byers JE (2005) Marine reserves enhance abundance but not competitive impacts of a harvested nonindigenous species. Ecology 86:487-500

Camphuysen KCJ, Ens BJ, Heg D, Hulscher JB, Van Der Meer J, Smit CJ (1996) Oystercatcher Haematopus ostralegus winter mortality in The Netherlands: the effect of severe weather and food supply. Ardea 84: 469-492

Camphuysen CJ, Berrevoets CM, Cremers HJWM, Dekinga A and others (2002) Mass mortality of common eiders (Somateria mollissima) in the Dutch Wadden Sea, winter 1999/2000: starvation in a commercially exploited wetland of international importance. Biol Conserv 106: 303-317

* Cesar CP, Frid CLJ (2009) Effects of experimental smallscale cockle (Cerastoderma edule L.) fishing on ecosystem function. Mar Ecol 30:123-137

Collie JS, Hall SJ, Kaiser MJ, Poiner IR (2000) A quantitative analysis of fishing impacts on shelf-sea benthos. J Anim Ecol 69:785-798

Dayton PK, Thrush SF, Agardy MT, Hofman RJ (1995) Environmental effects of marine fishing. Aquat Conserv 5: 205-232

Dernie KM, Kaiser MJ, Warwick RM (2003) Recovery rates of benthic communities following physical disturbance. J Anim Ecol 72:1043-1056

dit Durell SE, Stillman RA, Caldow RWG, McGrorty S, West
AD, Humphreys J (2006) Modelling the effect of environmental change on shorebirds: a case study on Poole Harbour, UK. Biol Conserv 131:459-473

Ens BJ, Smaal A, De Vlas J (2004) The effects of shellfish fishery on the ecosystems of the Dutch Wadden Sea and Oosterschelde. Rapportnr 2004.031. Rijkswaterstaat, RIKZ, Den Haag

FAO (Food and Agriculture Organization of the United Nations) (2014) The state of world fisheries and aquaculture. Food and Agriculture Organization of the United Nations, Rome

Ferns PN, Rostron DM, Siman HY (2000) Effects of mechanical cockle harvesting on intertidal communities. J Appl Ecol 37:464-474

Folk RL (1954) The distinction between grain size and mineral composition in sedimentary-rock nomenclature. J Geol 62:344-359

Folke C, Carpenter S, Walker B, Scheffer M, Elmqvist T, Gunderson L, Holling CS (2004) Regime shifts, resilience, and biodiversity in ecosystem management. Annu Rev Ecol Evol Syst 35:557-581

Goss-Custard JD, Stillman RA, West AD, Caldow RW, Triplet P, dit Durell SE, McGrorty S (2004) When enough is not enough: shorebirds and shellfishing. Proc R Soc Lond B Biol Sci 271:233-237

KGoss-Custard JD, West AD, Yates MG, Caldow RWG and others (2006) Intake rates and the functional response in shorebirds (Charadriiformes) eating macro-invertebrates. Biol Rev Camb Philos Soc 81:501-529

Griffiths J, Dethier MN, Newsom A, Byers JE, Meyer JJ, Oyarzun F, Lenihan H (2006) Invertebrate community responses to recreational clam digging. Mar Biol 149: 1489-1497

Hall SJ (1994) Physical disturbance and marine benthic communities: life in unconsolidated sediments. Oceanogr Mar Biol Ann Rev 32:179-239

* Halpern BS (2003) The impact of marine reserves: Do reserves work and does reserve size matter? Ecol Appl 13: S117-S137

*Halpern BS, Warner RR (2002) Marine reserves have rapid and lasting effects. Ecol Lett 5:361-366

*Handley SJ, Willis TJ, Cole RG, Bradley A, Cairney DJ, Brown SN, Carter ME (2014) The importance of benchmarking habitat structure and composition for understanding the extent of fishing impacts in soft sediment ecosystems. J Sea Res 86:58-68

Harding JM, Mann R (1999) Fish species richness in relation to restored oyster reefs, Piankatank River, Virginia. Bull Mar Sci 65:289-299

Heck KL, Able KW, Roman CT, Fahay MP (1995) Composition, abundance, biomass, and production of macrofauna in a New England estuary: comparisons among eelgrass meadows and other nursery habitats. Estuar Coast 18: 379-389

*Hughes KM, Kaiser MJ, Jennings S, McConnaughey RA and others (2014) Investigating the effects of mobile bottom fishing on benthic biota: a systematic review protocol. Environ Evid 3:23

Jennings S, Kaiser MJ (1998) The effects of fishing on marine ecosystems. Adv Mar Biol 34:201-352

Kaiser MJ, Edwards DB, Armstrong PJ, Radford K, Lough NEL, Flatt RP, Jones HD (1998) Changes in megafaunal benthic communities in different habitats after trawling disturbance. ICES J Mar Sci 55:353-361 
Kaiser MJ, Broad G, Hall SJ (2001) Disturbance of intertidal soft-sediment benthic communities by cockle hand raking. J Sea Res 45:119-130

Kaiser MJ, Collie JS, Hall SJ, Jennings S, Poiner IR (2002) Modification of marine habitats by trawling activities: prognosis and solutions. Fish Fish 3:114-136

Kaiser MJ, Clarke KR, Hinz H, Austen MCV, Somerfield PJ, Karakassis I (2006) Global analysis of response and recovery of benthic biota to fishing. Mar Ecol Prog Ser 311:1-14

Kang CK, Sauriau PG, Richard P, Blanchard GF (1999) Food sources of the infaunal suspension-feeding bivalve Cerastoderma edule in a muddy sandflat of MarennesOléron Bay, as determined by analyses of carbon and nitrogen stable isotopes. Mar Ecol Prog Ser 187:147-158

Koricheva J, Gurevitch J, Mengersen K (2013) Handbook of meta-analysis in ecology and evolution. Princeton University Press, Princeton, NJ

Kraan C, Piersma T, Dekinga A, Koolhaas A, Van der Meer J (2007) Dredging for edible cockles (Cerastoderma edule) on intertidal flats: short-term consequences of fisher patch-choice decisions for target and non-target benthic fauna. ICES J Mar Sci 64:1735-1742

Levin LA (1984) Life history and dispersal patterns in a dense infaunal polychaete assemblage: community structure and response to disturbance. Ecology 65: $1185-1200$

Marine Stewardship Council (2016) Vietnam's Ben Tre hand gathered clam fishery proves it's sustainable, again. https://www.msc.org/newsroom/news/vietnams-ben-trehand-gathered-clam-fishery-proves-its-sustainable-again (accessed 13 June 2017)

Martín J, Puig P, Palanques A, Ribó M (2014) Trawlinginduced daily sediment resuspension in the flank of a Mediterranean submarine canyon. Deep Sea Res II 104: 174-183

McLachlan A (1996) Physical factors in benthic ecology: effects of changing sand particle size on beach fauna. Mar Ecol Prog Ser 131:205-217

* Möllmann C, Lindegren M, Blenckner T, Bergström L and others (2014) Implementing ecosystem-based fisheries management: from single-species to integrated ecosystem assessment and advice for Baltic Sea fish stocks. ICES J Mar Sci 71:1187-1197

Nelson KA, Leonard LA, Posey MH, Alphin TD, Mallin MA (2004) Using transplanted oyster (Crassostrea virginica) beds to improve water quality in small tidal creeks: a pilot study. J Exp Mar Biol Ecol 298:347-368

Newell RI (2004) Ecosystem influences of natural and cultivated populations of suspension-feeding bivalve molluscs: a review. J Shellfish Res 23:51-62

Norkko A, Thrush SF, Hewitt JE, Cummings VJ and others (2002) Smothering of estuarine sandflats by terrigenous clay: the role of wind-wave disturbance and bioturbation in site-dependent macrofaunal recovery. Mar Ecol Prog Ser 234:23-42

Pauly D (1995) Anecdotes and the shifting baseline syndrome of fisheries. Trends Ecol Evol 10:430

Pearson T, Rosenberg R (1978) Macrobenthic succession in relation to organic enrichment and pollution of the marine environment. Oceanogr Mar Biol Annu Rev 16: 229-311

Piersma T, Koolhaas A, Dekinga A, Beukema JJ, Dekker R, Essink K (2001) Long-term indirect effects of mechanical cockle-dredging on intertidal bivalve stocks in the Wadden Sea. J Appl Ecol 38:976-990

Pikitch EK, Santora C, Babcock EA, Bakun A and others (2004) Ecosystem-based fishery management. Science 305:346-347

* Pranovi F, Da Ponte F, Raicevich S, Giovanardi O (2004) A multidisciplinary study of the immediate effects of mechanical clam harvesting in the Venice Lagoon. ICES J Mar Sci 61:43-52

* Roberts T, Jones PJ (2009) Shellfishing, eider ducks, and nature conservation on the Wash: questions raised by a fractured partnership. Soc Nat Resour 22:538-553

* Rutten AL, Oosterbeek K, Ens BJ, Verhulst S (2006) Optimal foraging on perilous prey: risk of bill damage reduces optimal prey size in oystercatchers. Behav Ecol 17: 297-302

* Sciberras M, Hinz H, Bennell JD, Jenkins SR, Hawkins SJ, Kaiser MJ (2013) Benthic community response to a scallop dredging closure within a dynamic seabed habitat. Mar Ecol Prog Ser 480:83-98

* Scyphers SB, Powers SP, Heck KL Jr, Byron D (2011) Oyster reefs as natural breakwaters mitigate shoreline loss and facilitate fisheries. PLOS ONE 6:e22396

Skilleter GA, Zharikov Y, Cameron B, McPhee DP (2005) Effects of harvesting callianassid (ghost) shrimps on subtropical benthic communities. J Exp Mar Biol Ecol 320: 133-158

Smit C, Dankers N, Ens B, Meijboom A (1998) Birds, mussels, cockles and shellfish fishery in the Dutch Wadden Sea: how to deal with low food stocks for eiders and oystercatchers? Senckenb Marit 29:141-153

* Sousa Leitão FM, Baptista Gaspar M (2007) Immediate effect of intertidal non-mechanised cockle harvesting on macrobenthic communities: a comparative study. Sci Mar 71:723-733

Stillman RA, Wood KA (2013) Towards a simplified approach for assessing bird food requirements on shellfisheries. A report to the Welsh Government. Bournemouth University, Poole

* Stillman RA, West AD, Goss-Custard JD, Caldow RW and others (2003) An individual behaviour-based model can predict shorebird mortality using routinely collected shellfishery data. J Appl Ecol 40:1090-1101

* Stillman RA, Moore JJ, Woolmer AP, Murphy MD and others (2010) Assessing waterbird conservation objectives: an example for the Burry Inlet, UK. Biol Conserv 143:2617-2630

* Stillman RA, Wood KA, Goss-Custard JD (2016) Deriving simple predictions from complex models to support environmental decision-making. Ecol Model 326:134-141

Stokesbury KD, Baker EP, Harris BP, Rheault RB (2011) Environmental impacts related to mechanical harvest of cultured shellfish. In: Shumway SE (ed) Shellfish aquaculture and the environment. Wiley-Blackwell, Oxford, p 319-338

* Taghon GL (1982) Optimal foraging by deposit-feeding invertebrates: roles of particle size and organic coating. Oecologia 52:295-304

* Tang Q, Zhang J, Fang J (2011) Shellfish and seaweed mariculture increase atmospheric $\mathrm{CO}_{2}$ absorption by coastal ecosystems. Mar Ecol Prog Ser 424:97-104

*Van Hoey G, Degraer S, Vincx M (2004) Macrobenthic community structure of soft-bottom sediments at the Belgian Continental Shelf. Estuar Coast Shelf Sci 59:599-613 
Van Roomen M, Van Turnhout C, Van Winden E, Koks B, Goedhart P, Leopold M, Smit C (2005) Trends in benthivorous waterbirds in the Dutch Wadden Sea 19752002: large differences between shellfish-eaters and worm-eaters. Limosa 78:21-38

Verhulst S, Oosterbeek K, Rutten A, Ens B (2004) Shellfish fishery severely reduces condition and survival of oystercatchers despite creation of large marine protected areas. Ecol Soc 9:17

Viechtbauer W (2010) Conducting meta-analyses in R with the metafor package. J Stat Softw 36:1-48

Watson GJ, Farrell P, Stanton S, Skidmore LC (2007) Effects

Editorial responsibility: Antony Underwood,

Sydney, New South Wales, Australia of bait collection on Nereis virens populations and macrofaunal communities in the Solent, UK. J Mar Biol Assoc UK 87:703-716

Watson GJ, Murray JM, Schaefer M, Bonner A (2017) Bait worms: a valuable and important fishery with implications for fisheries and conservation management. Fish Fish 18:374-388

*Wynberg RP, Branch GM (1994) Disturbance associated with bait-collection for sandprawns (Callianassa kraussi) and mudprawns (Upogebia africana): long-term effects on the biota of intertidal sandflats. J Mar Res 52:523-558

Submitted: February 27, 2017; Accepted: September 27, 2017 Proofs received from author(s): November 20, 2017 